\title{
A TYK2 Gene Mutation c.2395G >A Leads to TYK2 Deficiency: A Case Report and Literature Review
}

\author{
Peilin Wu ${ }^{1}$, Suqing Chen ${ }^{1 *}$, Bin $W u^{1}$, Junhong Chen ${ }^{1}$ and $G e L v^{2}$ \\ ${ }^{1}$ The Pediatric Department, The First Affiliated Hospital of Fujian Medical University, Fuzhou, China, ${ }^{2}$ Chongqing Key \\ Laboratory of Child Infection and Immunity, Children's Hospital of Chongqing Medical University, Chongqing, China
}

\section{OPEN ACCESS}

Edited by:

Jordi Pérez-Tur,

Institute of Biomedicine of

Valencia, Spain

Reviewed by:

Alexandra Freeman,

National Institutes of Health (NIH),

United States

Ryuta Muromoto,

Hokkaido University, Japan

Stuart G. Tangye,

Garvan Institute of Medical

Research, Australia

*Correspondence:

Suqing Chen

fyekcsq@163.com

Specialty section:

This article was submitted to

Genetic Disorders,

a section of the journal

Frontiers in Pediatrics

Received: 08 August 2019

Accepted: 22 April 2020

Published: 27 May 2020

Citation:

Wu P, Chen S, Wu B, Chen J and Lv G (2020) A TYK2 Gene Mutation

c.2395G > A Leads to TYK2

Deficiency: A Case Report and

Literature Review.

Front. Pediatr. 8:253.

doi: 10.3389/fped.2020.00253
Tyrosine kinase 2 (TYK2) deficiency was formerly defined in patients suffering from autosomal recessive hyperimmunoglobulin E syndrome (AR-HIES). In recent years, it was proposed that human TYK2 deficiency is probably not a common cause of the AR-HIES but a distinctive illness object. In the current work, a recessive TYK2 deficiency is reported in a patient suffering from BCG disease and recurrent respiratory infection. It was implied that this patient carried novel missense homozygous mutation (c.2395G >A, p. G799R) in the TYK2. Both the in vivo and in vitro experiments indicated the inhibition effects of the c.2395G $>$ A homozygous mutation on the TYK2 gene and protein expression. By literature review, we summarized the clinical manifestations, gene mutations, and related cytokine responses of formerly reported patients possessing TYK2 deficiency. The core manifestation of these patients is infected by intracellular pathogens, such as mycobacteria and/or viruses. Therefore, the possibility of TYK2 deficiency should be considered when a patient has repeated intracellular bacteria (including tuberculosis bacillus infection), repeated viral infection or eczema.

Keywords: TYK2 deficiency, primary immunodeficiency, hyperimmunoglobulin E syndrome, BCG, mutation

\section{BACKGROUND}

Tyrosine kinase 2 (TYK2), a member of the Janus kinase (JAK) family, is associated with the receptors of type I interferon (IFN), interleukin (IL)-6, IL-10, IL-12, and IL-23, has a key role in the signal transduction of these cytokines, most prominently IFN $\alpha / \beta(1,2)$. IFN and some other cytokines, which are the critical roles in multiple adaptive and innate immune responses, transduce signals through the JAK-STAT path. Type I interferons signal through IFNAR1 and IFNAR2, which, respectively, associate with TYK2 and JAK1. When the cytokines bind and induce the dimerization of their receptors, receptor-associated JAKs become phosphorylated and activated. Subsequently, the activated JAKs can phosphorylate the downstream substrates, the signal transducers and activators of transcription (STAT) molecules, then dimerizing and translocating to the nucleus for activating the particular genes transcription $(3,4)$. Minegishi et al. reported the first TYK2-deficient patient (P1) in 2006. The patient was Japanese with the triad of HIES signs (5). Interestingly, unlike P1, the HIES features were not displayed by the other 7 TYK2-deficient patients (P2-P8) recently recognized by Kreins et al. (1). No high serum IgE concentration, atopy, nor staphylococcal disease observed in them. They exhibited intracellular bacteria and/or viral infections, and the most typical feature is BCG disease. Therefore, it was proposed that human TYK2 deficiency is a distinctive PID entity clinically and different from the formerly identified patients with AR-HIES (6). According to the categorization reported by the IUIS, International Union of Immunological Societies, TYK2 deficiency was classified into Mendelian Susceptibility to Mycobacterial Disease (MSMD) $(7,8)$. 
In this study, we report a novel TYK2 gene mutation c. $2395 \mathrm{G}>\mathrm{A}$ in a Chinese patient with BCG disease using whole-exome sequencing analysis. We further summarized the clinical manifestations, gene mutations, and related cytokine responses of all reported patients with TYK2 deficiency to review the knowledge about TYK2 deficiency. This study was performed according to the Declaration of Helsinki (1975) with approval from the local ethics committee (ID: MRCTA, ECFAH of FMU [2019]218) of the first affiliated hospital of Fujian medical university.

\section{CASE PRESENTATION}

\section{History}

The patient was a boy at the age of 1 year and 11 months, the second child in the family (parents are young and nonconsanguineous), who was born in 2016 and vaccinated with BCG vaccine on the third day after birth. He was hospitalized in our hospital for bacterial pneumonia. After intradermal injection of BCG, repeated abscess and ulceration occurred at the injection site and gradually healed at 10 months. At the age of 14 months, he was hospitalized with enlarged left axillary lymph nodes. The diagnosis of BCG associated lymph node tuberculosis was made with positive staining for acid-fast bacilli and isolated Mycobacterium Bovis BCG from the discharging axillary sinuses. Chest X-ray showed no lung involvement. After the drainage of lymph node and external application of Chinese herbal medicine, the regional lymphadenopathy regressed to normal. He also suffered from recurrent respiratory tract infections (had pneumonia or upper respiratory tract infection every 12 months) and diarrhea since the age of 6 months (sensitive to the food firstly contacted). Pathogens found during multiple hospitalizations included Salmonella, Mycoplasma pneumonia, and Mycobacterium Bovis BCG. No considerable viral or fungal infections have happened so far. No high serum IgE concentration, atopy, staphylococcal illness, or lymphopenia was found for him. He started to say some simple words at the age of 3 years and 4 months with normal motor development. Physical examination revealed a small head circumference. His mother's brother and sister coughed and repeatedly wheezed in childhood.

TABLE 1 | Immunologic parameters of our patient.

\begin{tabular}{lcc}
\hline Immunologic parameters & Patient & Normal value \\
\hline Absolute lymphocyte count, $/ \mathrm{mm}^{3}$ & 5,550 & $800-4,000$ \\
Absolute eosinophil count, $/ \mathrm{mm}^{3}$ & 270 & $20-500$ \\
IgG, g/L & 3.43 & $3-10$ \\
IgM, g/L & 1.94 & $0.45-2.39$ \\
IgA, g/L & 0.23 & $0.14-1.08$ \\
IgE, IU/ml & 27.4 & $\leq 49$ \\
T cells, CD3 ${ }^{+}, \%$ & 63.2 & $53.88-72.87$ \\
B cells, CD19+, \% & 26.6 & $7.21-20.90$ \\
CD4 ${ }^{+}$cells, \% & 35.9 & $24.08-42.52$ \\
CD8+ cells, \% & 19.3 & $19.00-32.51$ \\
Natural Killer cells, CD3-CD16 /CD56 ${ }^{+}, \%$ & 3.6 & $13.23-26.39$
\end{tabular}

\section{Immunologic Assessments}

These data were collected when the patient was 1 year and 11 months old. The absolute eosinophil count and lymphocyte count were normal. Immunoglobin: serum IgG, IgA, IgE, and IgM levels were normal. Lymphocyte classification: the percentage of $\mathrm{CD}^{+} \mathrm{T}$ cells, $\mathrm{CD} 3^{+} \mathrm{CD} 4^{+} \mathrm{CD} 8^{-} \mathrm{T}$ cells, $\mathrm{CD} 3^{+} \mathrm{CD} 8^{+} \mathrm{CD} 4^{-} \mathrm{T}$ cells were within the range of normal, whereas the percentage of $\mathrm{CD} 45^{-} \mathrm{CD} 19+$ cells were higher than the normal range, and $\mathrm{CD}^{-} \mathrm{CD} 16 / \mathrm{CD}^{-} 6^{+}$cells were lower (Table 1).

\section{Pathogens of Respiratory Tract Infection}

Data was collected after the patient was hospitalized. The results showed positive - IgM antibodies to the influenza A \& B virus. which suggested the current or recent infection. IgM antibodies to $\mathrm{m}$. pneumoniae and $\mathrm{m}$. pneumoniae antibodies are positive (1: 160), which revealed the existence of mycoplasma pneumonia (Table 2).

\section{Gene Mutation Screening}

We investigated the TYK2 gene of the members of this family except for the brother by WES (whole exon sequencing). Mutations were found in four genes, including TYK2 (c.2395G>A, p.G799R, hom), CFH (c.2089C>T, p.L697F, het), LRRC8A (c.1250G >A, p.R417Q, het) and NIPBL (c.557527_c.5575-26delCT, -, het). The pathogenic evidences of these mutations in CFH, LRRC8A and NIPBL are insufficiency, but the possible variations of pathogenicity could not be excluded. Sequence analysis demonstrated the homozygous missense mutation in the exon 17 of the TYK2 gene of the patient, which was heterozygous in his parents (Figure 1).

\section{TYK2 Mutation (c.2395G >A) in vivo and in vitro}

qRT-PCR was carried out to detect the expression of TYK2 in patient-derived cells with the forward primer $\left(5^{\prime}-3^{\prime}\right.$ CAGATCAGACAGCACAGGGG) and the reverse primer $\left(5^{\prime}-3^{\prime}\right.$ GCAGTCCTTGAAGCTGGTCT). The results showed that this mutation leads to a decrease of TYK2 mRNA expression (Figure 2A). Besides, the western blot results showed that no TYK2 protein expression found in the patient (Figure 2B). To verify the effects of c.2395G $>$ A on TYK2 deficiency, an in

TABLE 2 | Pathogen detection results.

\begin{tabular}{lll}
\hline IgM-type antibodies & Patient & Normal value \\
\hline IgM to respiratory syncytial virus & negative $(-)$ & negative $(-)$ \\
IgM to adenovirus & negative $(-)$ & negative $(-)$ \\
IgM to influenza A virus & positive $(+)$ & negative $(-)$ \\
IgM to influenza B virus & positive $(+)$ & negative $(-)$ \\
IgM to parainfluenza virus & negative $(-)$ & negative $(-)$ \\
IgM to M. pneumoniae & positive $(+)$ & negative $(-)$ \\
IgM to M. tuberculosis & negative $(-)$ & negative $(-)$ \\
IgM to legionella pneumophila & negative $(-)$ & negative $(-)$ \\
M. pneumoniae antibody (mp ab) & $1: 160$ & $1: 40$
\end{tabular}




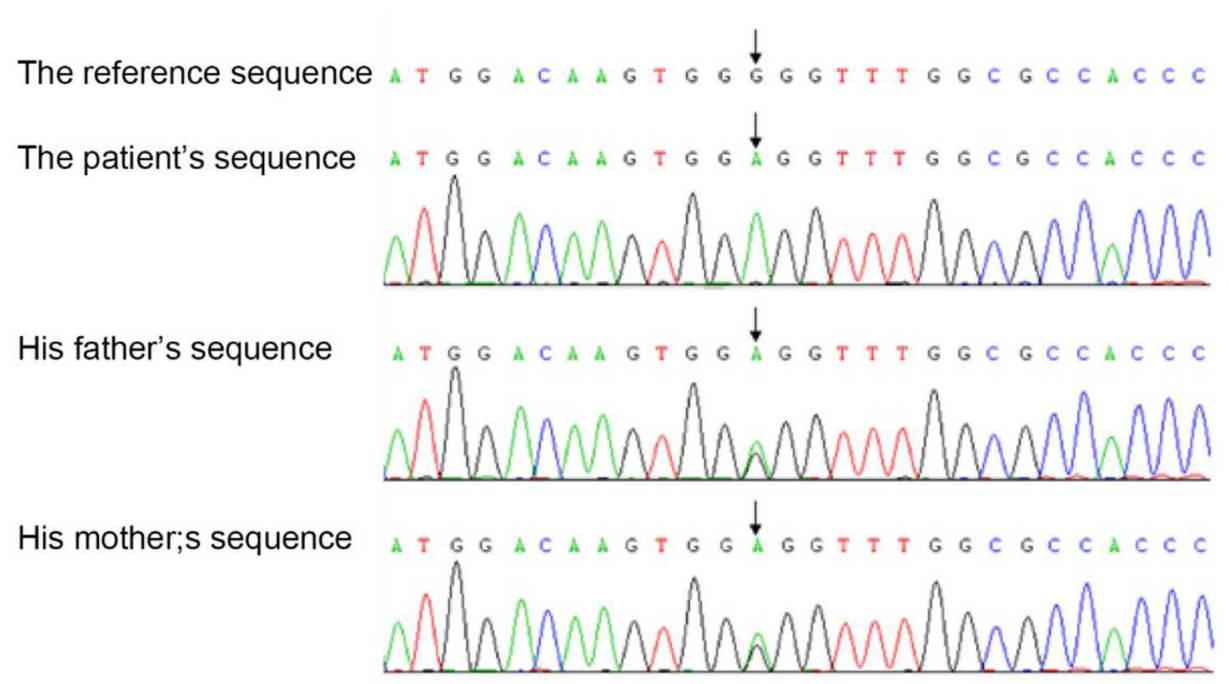

FIGURE 1 | A homozygous missense mutation in exon 17 of the TYK2 gene in our patient.
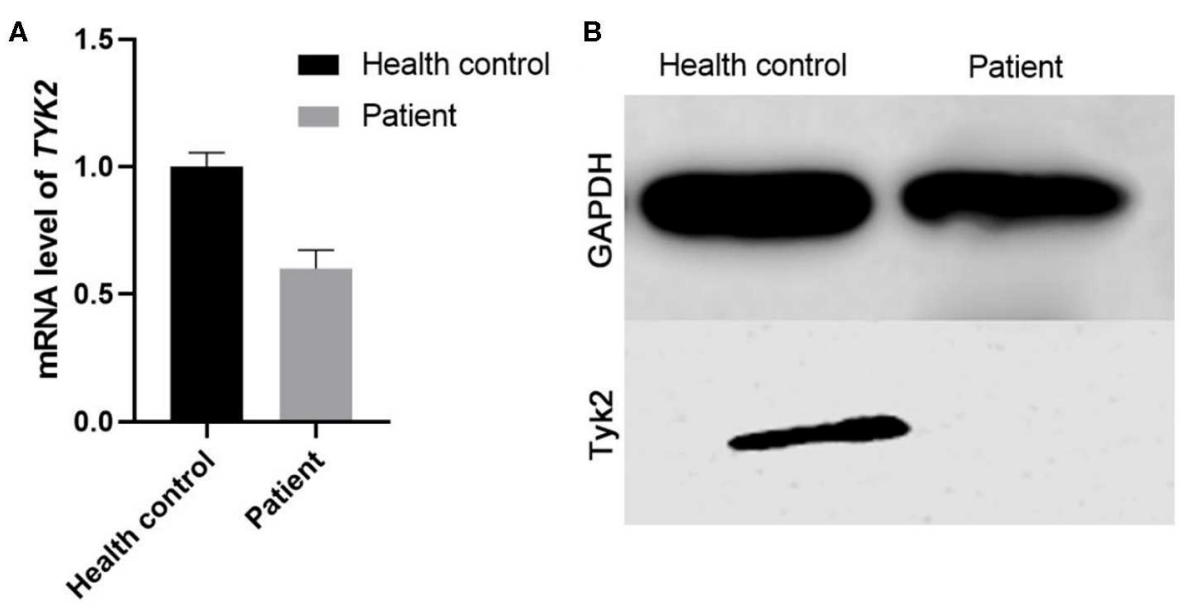

FIGURE 2 | The expression of TYK2 in these family members. (A) The qRT-PCR results of the patient and health control. (B) Western blot analysis results of Tyk2 protein in patient and health control.

vitro experiment was carried out. The effects of c.2395G $>$ A mutation on the TYK2 gene and protein expression were revealed using two types of plasmids: p3XFLAG-CMV-7.1TYK2 (FLAG-TYK2) and pEGFP-N1-TYK2 (TYK2-GFP). We investigated c.2395G $>$ A (p.G799R) mutant introduced into the HEK293T cell line (Figure 3A). The qRT-PCR results showed that this c.2395G $>$ A mutant decreased the expression of FLAG-TYK2 and TYK2-GFP (Figure 3B). To go along with this, this mutant also decreased the expressed protein of FLAG-TYK2 and TYK2-GFP in the western blot analysis (Figure 3C).

\section{DISCUSSION}

\section{Clinical Manifestations}

Including our patient, there are 12 patients reported with TYK2 deficiency $(1,2,5,9)$ (Table 3 ), with the average age at diagnosis of 10.8 years old. Seven patients (58\%) suffered from intracellular bacterial infections. M. tuberculosis was observed in 2 cases $(17 \%)$. Seven patients had recurrent virus infections (58\%). Rash or atopic dermatitis eczema was observed in 2 patients (17\%). Markedly increased serum IgE occurred in 3 cases (25\%), and EBV-related B lymphoma and $\mathrm{T}$ cells lymphopenia were reported in 2 cases (17\%). Different from type I high IgE syndrome caused by STAT3 mutation, none of the 12 patients had special facial features, abnormal bone development or pathological fractures, delayed deciduous tooth loss, or aneurysms.

\section{Pathogenesis}

The mammalian JAK family has four members: JAK1, JAK2, JAK3 and tyrosine kinase 2 (TYK2). Tyk2 as an essential element, 


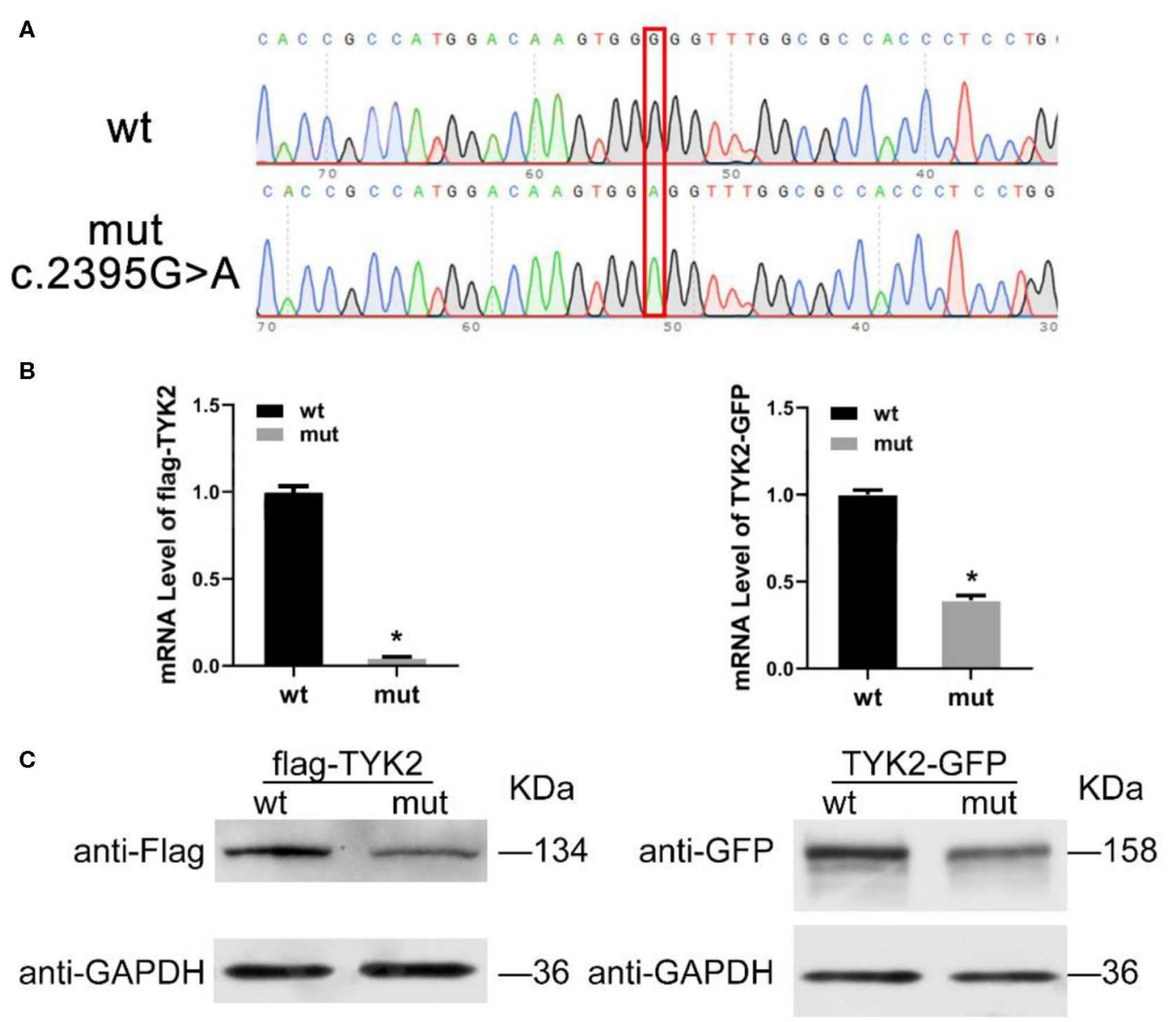

FIGURE 3 | Expression of TYK2 in wild type and c.2395G>A mutant HEK293T cell line. (A) The sanger analysis results of wild type and c.2395G >A mutant HEK293T cell; (B) mRNA expression of FLAG-TYK2 and TYK2-GFP in both wild type and c.2395G>A mutant HEK293T cell; (C) Western blot analysis results of FLAG-TYK2 and TYK2-GFP in both wild type and c.2395G>A mutant HEK293T cell.

which is activated by an array of cytokine receptors in IL12 and type I-IFN signaling. A mutation in this gene has been associated with HIES (5, 10). In this case, c.2395G $>$ A is a missense mutation that causes the amino acid to change from $G$ to $R$, which may restrict the function of TYK2 protein. Our results also support this inference, and we did observe decreases in gene expression and protein levels in patient-derived cells and HEK293T cells. Although HEK293T cells have lower background factors, they still cannot fully simulate patient-derived cells, so the results of the two cells are somewhat different, but at least the trends of both cell types are consistent. For its pathogenic mechanism, viral and/or mycobacterial infections are the main clinical phenotypes of TYK2 deficiency, initiated by diminished reactions to IL-12 and IFN- $\alpha / \beta$. A key cytokine in generating and regulating the cellular immune response needed for the elimination of intracellular pathogens from macrophages is IFN- $\gamma$. TYK2 mediates signal transduction between cytokine receptors and STATs. Both IL-12 and IL-23 can promote the production of IFN $-\gamma$. TYK2 mutation weakened the response of NK and T cells to IL-12 and IL-23, resulting in insufficient IFN- $\gamma$ creation $(11,12)$. When cells cannot secrete normal levels of IFN- $\gamma$, they are vulnerable to poorly pathogenic mycobacteria, and develop into MSMD (12). In addition, the main factor of the innate antiviral defense of all cells is represented by IFN- $\alpha / \beta$ (13). The largely impaired or abolished of IFN- $\alpha / \beta$ responses probably contribute to the incremented sensitivity to viral infections. However, virus control via type-III IFN (IFN- $\lambda$ ) signals could be a compensatory role contributing to the mild phenotype in TYK2 deficient patients regardless of an intense decrease in IFN- $\alpha / \beta$ mediated antiviral activity (14). Nemoto reported a recessive partial TYK2 deficiency in two siblings who presented with T-cell lymphopenia characterized by low naïve CD4+ T-cell counts and who developed EBV-associated B-cell lymphoma (2). TYK2deficient patients presented with infections associated with the herpesvirus family (1), thus, TYK2-deficient patients might be susceptible to EBV (15). Correspondingly, it was observed that not all TYK2-deficient patients had poor control of the virus. Among these informative patients, no incremented susceptibility to viral infections was found nearly in half of them. Very mild 
TABLE 3 | Information about reported TYK2-deficient patients.

\begin{tabular}{|c|c|c|c|c|c|c|c|c|c|c|c|c|c|}
\hline & First author & Sex & Country & Age & $\begin{array}{l}\text { Atopy/ } \\
\text { dermatitis }\end{array}$ & $\begin{array}{l}\text { High IgE } \\
\text { levels }\end{array}$ & $\begin{array}{l}\text { S. aureus } \\
\text { infection }\end{array}$ & $\begin{array}{l}\text { Viral } \\
\text { infection }\end{array}$ & $\begin{array}{l}\text { Intracellular } \\
\text { bacterial } \\
\text { infection }\end{array}$ & $\begin{array}{l}\text { Fungal } \\
\text { infection }\end{array}$ & $\begin{array}{l}\text { BCG } \\
\text { vaccination }\end{array}$ & Gene mutation & Protein mutation \\
\hline P1 & Minegishi & M & Japan & 22 & yes & yes & yes & HSV, PI3, MC & $\begin{array}{l}\text { BCG } \\
\text { Salmonella }\end{array}$ & C. albicans & yes & $\begin{array}{l}\text { Exon } \\
4 \text { c.550_553delGCTT }\end{array}$ & $\mathrm{C} 70 \mathrm{Hfs} \mathrm{X} 21$ \\
\hline P2 & Kreins & M & Turkey & 17 & no & no & no & VZV & BCG, Brucella & no & yes & Exon 16 c.2303_2311del & L767X \\
\hline P3 & Kreins & $\mathrm{F}$ & Morocco & 14 & no & no & no & no & $\begin{array}{l}\text { M. } \\
\text { tuberculosis }\end{array}$ & no & yes & Exon23c.3318_3319insC & T1106HfsX4 \\
\hline P4 & Kreins & M & Morocco & 14 & no & no & no & unknown & unknown & no & yes & Exon23c.3318_3319insC & T1106HfsX4 \\
\hline P5 & Kreins & M & Iran & 5 & no & no & no & no & $B C G$ & no & yes & Exon5 c.462G>T & E154X \\
\hline P6 & Kreins & $\mathrm{F}$ & Iran & 2 & no & no & no & yes & $\mathrm{BCG}$ & no & yes & Exon5 c. $462 \mathrm{G}>\mathrm{T}$ & E154X \\
\hline P7 & Kreins & $\mathrm{F}$ & Iran & 9 & no & no & no & no & $\begin{array}{l}\text { M. } \\
\text { tuberculosis }\end{array}$ & no & yes & Exon3c.149delC & S50HfsX1 \\
\hline P8 & Kreins & M & Argentina & 11 & no & no & no & HSV & No & no & yes & Exon13 c.1912 C>T & R638X \\
\hline P9 & Fuchs & M & Kurdish & 5 & yes & yes & yes & no & No & no & no & Exon7 c.647delC & P216RfsX14 \\
\hline P10 & Nemoto & M & unknown & 15 & no & no & no & $\begin{array}{l}\text { EBV- } \\
\text { associated } \\
\text { B-cell } \\
\text { lymphoma, } \\
\text { varicella }\end{array}$ & No & no & yes & $\begin{array}{l}\text { compound heterozygous } \\
\text { mutations c.209_212 del } \\
\text { GCTT/c.691 C > T }\end{array}$ & C70SfsX21/R231W \\
\hline P11 & Nemoto & $\mathrm{F}$ & unknown & 14 & no & no & no & $\begin{array}{l}\text { EBV- } \\
\text { associated } \\
\text { B-cell } \\
\text { lymphoma, } \\
\text { Varicella }\end{array}$ & Unknown & no & yes & $\begin{array}{l}\text { compound heterozygous } \\
\text { mutations c.209_212 del } \\
\text { GCTT/c.691 C > T }\end{array}$ & C70SfsX21/R231W \\
\hline P12 & Peilin & $\mathrm{M}$ & China & 2 & no & no & no & Influenza virus & MP, BCG & no & yes & Exon17 c. $2395 \mathrm{G}>\mathrm{A}$ & G799R \\
\hline Total & & $M: F=8: 4$ & & 10.8 & 2/12 (0.17) & 2/12 (0.17) & $2 / 12(0.17)$ & 7/12 (0.58) & 7/12 (0.58) & 1/12 (0.08) & 11/12 (0.92) & & \\
\hline
\end{tabular}

BCG, Bacillus Calmette - Guerin; MP, mycoplasma pneumonia. 
candidiasis was found in P1 (restricted to a small number of episodes of slight oral candidiasis), not in P2-P11, and P12. The normal circulating IL17 T cells probably explained their apparent lack of CMC. The response to IL-23 is weakened but not stopped in TYK2-deficient patients. The susceptibility of the patient to extracellular bacteria might be described at least partly by the deficiency in IL-23 signaling. The high quantity of serum IgE and the atopic dermatitis-like skin inflammation in the patient could be caused by the hastened Th2 differentiation. TYK2 mutation probably promotes Th2 cell differentiation, leading to incremented producing of IL-4, IL-5, and IL-13, associated with atopic dermatitis and eczema. Besides, different mutation types may have different impact on the expression of TYK2, which lead to different patient characterization. Sequencing results implied that our patient carried novel missense homozygous mutation (c.2395G > A, p. G799R) in the TYK2. As a supplement, this mutation type was is included in the genome Aggregation Database (gnomAD), suggesting that this was not a private mutation. The CADD_score, GDI and MSC-SIFT_Score were A:25.6, 1605.550 and 0.243, respectively. Patients comes from consanguineous family might have other defects in addition to the TYK2 deficiency, which might influence the clinical phenotype.

\section{Differential Diagnosis}

All the 12 reported TYK2-deficient patients were infected by potential infection source (S. aureus infection/Viral infection/Intracellular bacterial infection/Fungal infection), which might be one of the important indicators for diagnosis. In addition, high serum IgE concentration is not universal in TYK2-deficient patients. In our TYK2 deficiency case, he was sensitive to the food firstly contacted, which indicated the intolerance to bacteria. Also, the family history of childhood wheezing cannot be ignored. Combined with the reported

\section{REFERENCES}

1. Kreins AY, Ciancanelli MJ, Okada S, Kong XF, Ramirez-Alejo N, Kilic SS, et al. Human TYK2 deficiency: Mycobacterial and viral infections without hyper-IgE syndrome. J Exp Med. (2015) 212:1641-62. doi: 10.1084/jem.20 140280

2. Nemoto M, Hattori H, Maeda N, Akita N, Muramatsu H, Moritani $\mathrm{S}$, et al. Compound heterozygous TYK2 mutations underlie primary immunodeficiency with T-cell lymphopenia. Sci Rep. (2018) 8:6956. doi: 10.1038/s41598-018-25260-8

3. Strobl B, Stoiber D, Sexl V, Mueller M. Tyrosine kinase 2 (TYK2) in cytokine signalling and host immunity. Front Biosci. (2011) 16:3214-32. doi: $10.2741 / 3908$

4. Snyder DT, Hedges JF, Jutila MA. Getting “inside” type I IFNs: type I IFNs in intracellular bacterial infections. J Immunol Res. (2017) 2017:9361802. doi: $10.1155 / 2017 / 9361802$

5. Minegishi Y, Saito M, Morio T, Watanabe K, Agematsu K, Tsuchiya S, et al. Human tyrosine kinase 2 deficiency reveals its requisite roles in multiple cytokine signals involved in innate and acquired immunity. Immunity. (2006) 25:745-55. doi: 10.1016/j.immuni.2006.09.009
TYK2 deficiency cases, we summary the main features of TYK2 deficiency: (a) TYK2 gene mutation; (b) Autosomal recessive inheritance; (c) The number of lymphocytes is normal, and multiple cytokine signaling defect; (d) Susceptibility to viruses or intracellular bacteria; (e) With/without elevated IgE. Therefore, the possibility of TYK2 deficiency should be considered when a patient has repeated intracellular bacteria (including tuberculosis bacillus infection), repeated viral infection or eczema, especially with a family history. An accurate genetic diagnosis could indicate susceptible pathogens conducive to accurate treatment.

\section{DATA AVAILABILITY STATEMENT}

All datasets made for this work are provided in the article/supplementary material.

\section{ETHICS STATEMENT}

This study was performed according to the Declaration of Helsinki (1975) with an approval from the local ethics committee (ID: MRCTA, ECFAH of FMU [2019]218) of the first affiliated hospital of Fujian medical university. Written informed consent was obtained from the parents of the participant for the publication of this case report.

\section{AUTHOR CONTRIBUTIONS}

PW, JC, and SC contributed to the literature searching. PW transcribed the first draft of the manuscript. SC and BW contributed to the modification of the discussion section in the manuscript. GL contributed to Western Blot verification experiment. All writers helped manuscript revision, read and approve the acquiesced version.
6. Woellner C, Schaffer AA, Puck JM, Renner ED, Knebel C, Holland SM, et al. The hyper IgE syndrome and mutations in TYK2. Immunity. (2007) 26:535-6. doi: 10.1016/j.immuni.2007.05.007

7. Bousfiha A, Jeddane L, Picard C, Ailal F, Bobby Gaspar H, Al-Herz W, et al. The 2017 IUIS phenotypic classification for primary immunodeficiencies. $J$ Clin Immunol. (2018) 38:129-43. doi: 10.1007/s10875-017-0465-8

8. Picard C, Bobby Gaspar H, Al-Herz W, Bousfiha A, Casanova JL, Chatila $\mathrm{T}$, et al. International union of immunological societies: 2017 primary immunodeficiency diseases committee report on inborn errors of immunity. $J$ Clin Immunol. (2018) 38:96-128. doi: 10.1007/s10875-017-0464-9

9. Kilic SS, Hacimustafaoglu M, Boisson-Dupuis S, Kreins AY, Grant AV, Abel L, et al. A patient with tyrosine kinase 2 deficiency without hyper-IgE syndrome. J Pediatr. (2012) 160:1055-7. doi: 10.1016/j.jpeds.2012.01.056

10. Minegishi $Y$, Karasuyama H. Hyperimmunoglobulin E syndrome and tyrosine kinase 2 deficiency. Curr Opin Allergy Clin Immunol. (2007) 7:506-9. doi: 10.1097/ACI.0b013e3282f1baea

11. Boisson-Dupuis S, Ramirez-Alejo N, Li Z, Patin E, Rao G, Kerner G, et al. Tuberculosis and impaired IL-23-dependent IFN- $\gamma$ immunity in humans homozygous for a common TYK2 missense variant. Sci Immunol. (2018) 3:eaau8714. doi: 10.1126/sciimmunol.aau8714 
12. Martinez Barricarte R, Markle J, Ma C, Deenick E, Ramirez-Alejo N, Mele F, et al. Human IFN- $\gamma$ immunity to mycobacteria is governed by both IL12 and IL-23. Sci Immunol. (2018) 3:eaau6759. doi: 10.1126/sciimmunol. aau6759

13. Biron C, Brossay L. NK cells and NKT cells in innate defense against viral infections. Curr Opin Immunol. (2001) 13:458-64. doi: 10.1016/S0952-7915(00)00241-7

14. Fuchs S, Kaiser-Labusch P, Bank J, Ammann S, Kolb-Kokocinski A, Edelbusch C, et al. Tyrosine kinase 2 is not limiting human antiviral type III interferon responses. Eur J Immunol. (2016) 46:2639-49. doi: 10.1002/eji.2016 46519

15. Ono S, Nakayama $M$, Kanegane $H$, Hoshino A, Shimodera S, Shibata H, et al. Comprehensive molecular diagnosis of Epstein-Barr virus-associated lymphoproliferative diseases using next-generation sequencing. Int J Hematol. (2018) 108:319-28. doi: 10.1007/s12185-018$2475-6$

Conflict of Interest: The authors declare that the research was conducted in the absence of any commercial or financial relationships that could be construed as a potential conflict of interest.

Copyright $\odot 2020 \mathrm{Wu}$, Chen, Wu, Chen and Lv. This is an open-access article distributed under the terms of the Creative Commons Attribution License (CC BY).

The use, distribution or reproduction in other forums is permitted, provided the original author(s) and the copyright owner(s) are credited and that the original publication in this journal is cited, in accordance with accepted academic practice. No use, distribution or reproduction is permitted which does not comply with these terms. 